\title{
Development of a job-exposure matrix (AsbJEM) to estimate occupational exposure to asbestos in Australia
}

Svein C van Oyen ${ }^{1} \dagger$, Susan Peters ${ }^{1} \dagger^{*}$, Helman Alfonso ${ }^{1,2}$, Lin Fritschi ${ }^{2}$, Nicholas H de Klerk ${ }^{1,3}$, Alison Reid ${ }^{1,2}$, Peter Franklin ${ }^{1}$, Len Gordon, Geza Benke ${ }^{4}$, AW (Bill) Musk $^{1,5}$

1. Occupational Respiratory Epidemiology, School of Population Health, University of Western Australia, Perth, Australia; 2. School of Public Health, Curtin University, Perth, Australia; 3. Telethon Kids Institute, University of Western Australia, Perth, Australia; 4. Department of Epidemiology and Preventive Medicine, Monash University, Melbourne, Australia; 5. Department of Respiratory Medicine, Sir Charles Gairdner Hospital, Perth, Australia

$\dagger$ Joint First Authors

*Author to whom correspondence should be addressed:

Susan Peters

Occupational Respiratory Epidemiology

School of Population Health, M431

University of Western Australia

35 Stirling Highway

Crawley WA 6009

Email: susan.peters@uwa.edu.au

Tel: +61 864887091

Fax: +61 864881611 


\section{ABSTRACT}

Introduction: Occupational exposure data on asbestos are limited and poorly integrated in Australia so that estimates of disease risk and attribution of disease causation are usually calculated from data that are not specific for local conditions.

Objective: To develop a job-exposure matrix (AsbJEM) to estimate occupational asbestos exposure levels in Australia, making optimal use of the available exposure data.

Method: A dossier of all available exposure data in Australia and information on industry practices and controls was provided to an expert panel consisting of three local industrial hygienists with thorough knowledge of local and international work practices. The expert panel estimated asbestos exposures for combinations of occupation, industry and time period. Intensity and frequency grades were estimated to enable the calculation of annual exposure levels for each occupation-industry combination for each time period. Two indicators of asbestos exposure intensity (mode and peak) were used to account for different patterns of exposure between occupations. Additionally, the probable type of asbestos fibre was determined for each situation.

Results: Asbestos exposures were estimated for 537 combinations of 224 occupations and 60 industries for four time periods (1943-66; 1967-86; 1987-2003; 22004). Workers in the asbestos manufacturing, shipyard and insulation industries were estimated to have had the highest average exposures. Up until 1986, 46 occupationindustry combinations were estimated to have had exposures exceeding the current Australian exposure standard of $0.1 \mathrm{f} / \mathrm{ml}$. Over $90 \%$ of exposed occupations were considered to have had exposure to a mixture of asbestos varieties including crocidolite.

Conclusion: The AsbJEM provides empirically-based quantified estimates of asbestos exposure levels for Australian jobs since 1943. This exposure assessment application will contribute to improved understanding and prediction of asbestosrelated diseases and attribution of disease causation.

KEYWORDS: exposure assessment; JEM; fibres; crocidolite; amosite; chrysotile; asbestos-related diseases; mesothelioma; asbestosis 


\section{INTRODUCTION}

Australia consumed large quantities of asbestos following World War II (Xu et al. 1985) and was for a time one of the world's largest producers of crocidolite, which is the most carcinogenic asbestos fibre type for mesothelioma (Hodgson and Darnton 2000). By 1954, Australia had the highest per capita asbestos consumption worldwide (Lin et al. 2007). Consumption peaked at 70,000 tonnes per year in 1975 (Musk and de Klerk 2004). Asbestos was banned from all building materials in Australia in 1989, although production and sale of all other asbestos products were not prohibited completely until 2003 (NOHSC 2005).

As a result of the extensive use of asbestos in the past, Australians have one of the highest rates of mesothelioma in the world. The male age-standardised incidence rate was 4.3 cases per 100,000 person-years in 2012 (Australian Mesothelioma Registry 2nd Annual Report 2012). The rate is particularly high in Western Australia, namely 7.2 per 100,000 person-years in 2012 (Australian Mesothelioma Registry 2nd Annual Report 2012), mainly due to the crocidolite that was mined at Wittenoom between 1943 and 1966 (Musk et al. 1992).

Although recent observations suggest that an increasing proportion of mesothelioma cases are caused by non-occupational exposures, by far the majority of mesothelioma cases are attributable to previous occupational exposure (Olsen et al. 2011; Rushton et al. 2012). In order to predict future cases of mesothelioma and other asbestos-related diseases, to estimate exposure-response relationships, to model risks taking into account dynamic patterns in exposure histories, and to attribute disease causation to asbestos exposure, detailed exposure assessment is essential (Lenters et al. 2011; Vermeulen and Chadeau-Hyam 2012). Lifetime exposure to asbestos therefore needs to be assessed on an individual basis to enable the estimation of cumulative exposure levels and time since first exposure. In order to quantify risks, quantitative exposure estimates based on measurement data are required. Obtaining such data is challenging due to their retrospective character and the wide range of workplaces in the general population.

Despite considerable production and use of asbestos, occupational exposure data have been limited and poorly integrated in Australia. Levels of exposure to crocidolite 
among Wittenoom miners have been assessed in detail (de Klerk et al. 1989), but due to the lack of asbestos exposure data in other industries, studies often had to rely on exposure surrogates such as job titles obtained from occupational histories or extrapolated estimates from international studies which may not be appropriate for Australian working conditions. A systematic approach to estimate occupational exposure to asbestos in Australian workplaces is required to make optimal use of these sparse data.

The aim of this study was to create a job-exposure matrix (JEM) for asbestos exposure under Australian working conditions, other than in the Wittenoom mine, since 1943 using all relevant and available data.

\section{METHODS}

\section{Occupational exposure information}

Local reports with results from area monitoring within workplace environments and personal occupational measurements were collected. Additionally, results from international studies were reviewed to provide additional guidance on industries where Australian exposure data were limited.

Airborne asbestos measurements were reported in 3,497 records in government documents, laboratory simulation records from occupational hygiene consultancies in Victoria, airborne fibre monitoring records from an occupational hygiene consultancy in Western Australia, and national and international publications (Table 1). The data included exposure measurements from 57 industries and 89 occupations from 19372007 in Australia, as well as records from Canada, France, Germany, Finland, Puerto Rico, Slovenia, Sweden, the United Kingdom (UK) and the United States (US). Taskspecific information was documented in 818 records. Nearly $70 \%$ of the reported measurements related to Australian exposure conditions.

\section{Exposure assessment process}

A panel of three experienced occupational hygienists, who were familiar with the Australian conditions with regards to asbestos use, was established. Under guidance of one of the authors $(\mathrm{SCvO})$, the expert panel was asked to examine the collected 
exposure information in order to assess the asbestos exposure for each combination of occupation, industry and time period.

Four time periods of interest were identified based on changes in Australian asbestos consumption and legislation: 1943-1966 when the Wittenoom crocidolite mine was in operation and crocidolite became increasingly available as a cheap construction material; 1967-1986 when asbestos health hazards were recognized and occupational exposure limits were introduced; 1987-2003 when the use of raw crocidolite was prohibited and further limitations and controls were placed on other types of asbestos; and $\geq 2004$ when all new asbestos use was prohibited.

The asbestos type was defined as the type of asbestos fibres to which workers within a particular occupation-industry-time period combination were most likely to have been exposed. The categories used were "amosite", "chrysotile", "mixture including crocidolite", "mixture not including crocidolite".

Exposure measures consisted of the intensity and frequency of asbestos exposure, estimated for both the 'mode exposure' and 'peak exposure'. Mode exposure was defined as the most common exposure in a particular job, when exposed above background level. Peak exposure was defined as a short-term intense exposure, arbitrarily set at 15 minutes. This peak exposure was considered to have occurred on the same day as the mode exposure.

Collected monitoring data results were not statistically modelled, but were used to assist the experts in the assignment of exposure intensity levels. The experts also took into account when, where and how measurements were taken, e.g. whether it were personal or area monitoring results. The majority of the airborne asbestos measurements were expressed as fibres per millilitre $(\mathrm{f} / \mathrm{ml})$ or an equivalent measure according to the membrane filter method for evaluating airborne asbestos fibres (NIOSH 1994). Some earlier estimates utilized airborne asbestos measurements in millions of particles per cubic foot (mppcf), but these were few and were therefore only used to provide an indication of the presence of exposure. 
Intensity of exposure was assigned in five categories, based on the mid-point of five exposure ranges according to the Australian Standard for asbestos exposure $(0.1 \mathrm{f} / \mathrm{ml}$ (Safe Work Australia 2011)) and expressed as a time-weighted average (TWA) for an 8 -hour working day. The estimated exposure levels were classified in the following categories: $0.0001 \mathrm{f} / \mathrm{ml}$ as background (Brown 2000); $0.05 \mathrm{f} / \mathrm{ml}(0.01-0.1 \mathrm{f} / \mathrm{ml}$ ) as low; $0.5 \mathrm{f} / \mathrm{ml}(0.1-1 \mathrm{f} / \mathrm{ml})$ as medium; $12 \mathrm{f} / \mathrm{ml}(1-25 \mathrm{f} / \mathrm{ml})$ as high; and $37.5 \mathrm{f} / \mathrm{ml}(25$ $50 \mathrm{f} / \mathrm{ml}$ ) as very high.

Frequency of exposure reflected the experts' assessment of the occurrence of exposure in a particular job or industry within a working year (240 days, assuming four weeks of holidays): annually (1 day/yr); biannually (2 days/yr); monthly (11 days/yr); weekly (48 days/yr); or daily (240 days/yr). Days represented a standard 8hour working shift.

The expert panel assessment process started with the selection of an industry. All available literature for that industry was then reviewed. Next, possible exposures were discussed by occupation within the industry, taking into consideration factors influencing exposure over time, such as changes in work practices, legislation, the introduction of controls and changes in the asbestos types which were used. Thus each industry-occupation-time period combination present in the AsbJEM was individually considered by the expert panel, until consensus was reached. The experts assigned categorical values of exposures. For example, the mode asbestos exposure of a carpenter in construction (1967-1986) was assessed as 'low' and 'weekly', with a peak exposure occurring once a month at a high level.

The annual average exposures were calculated for each industry-occupation combination by summing the peak, mode and background exposures, divided by the number of working days in a year (240):

- Peak exposure was calculated by multiplying peak intensity by peak frequency. The peak frequency variable was multiplied by a constant (15/480) allowing peak exposures to be expressed as 15 minutes of high exposure within a standard 8-hour working day (=480 minutes);

- Mode exposure was calculated by multiplying mode intensity by the number of mode days exposed in a year, subtracting the total time exposed to peak 
levels (since peak and mode exposures were considered to have occurred on the same days);

- Background exposure was calculated by subtracting the mode exposed days from the total number of days in the working year (240) and multiplied by the background level of $0.0001 \mathrm{f} / \mathrm{ml}$.

For example, in the case of a carpenter working in the construction industry the annual average exposure was $0.027 \mathrm{f} / \mathrm{ml}$ for each year from 1967 to 1986 . This was derived from a mode intensity of $0.05 \mathrm{f} / \mathrm{ml}$, a mode frequency of 48 days $/ \mathrm{yr}$, a peak intensity of $12 \mathrm{f} / \mathrm{ml}$, and a peak frequency of 11 days/yr. The remaining time their exposure level was set at background.

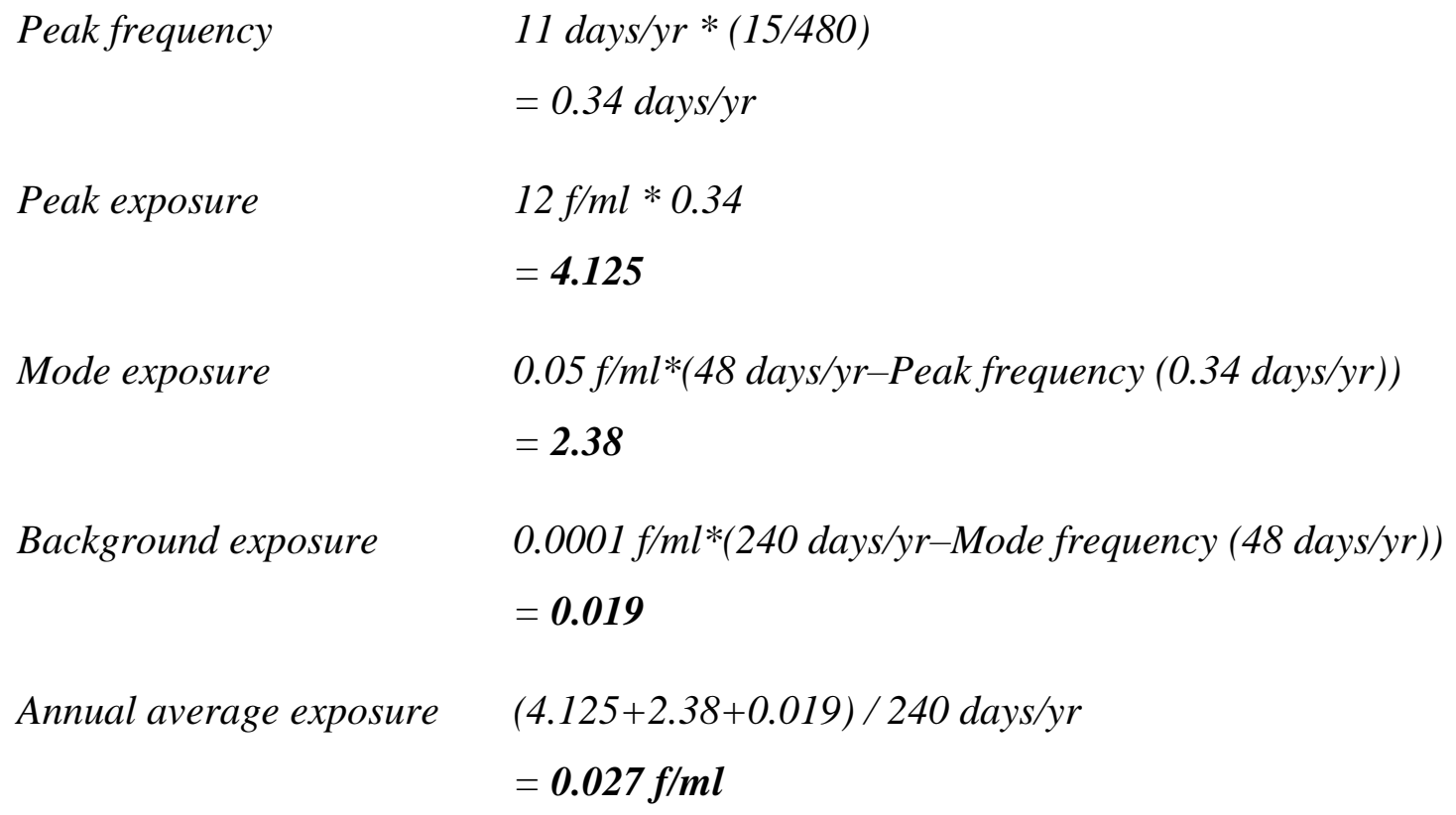

\section{RESULTS}

A total of 537 combinations of 224 occupations and 60 industries with potential exposure to asbestos were identified. Of these combinations, 486 were assessed to involve asbestos exposure levels above background level at any time period. The type of asbestos was most often $(>90 \%)$ considered to be a 'mixture of fibres including crocidolite' in the occupations where asbestos exposure levels were above background. The expert panel assigned the same categorical values to each job- 
industry combination for time periods 1 and 2 . Therefore the results for these two periods are presented together (1943-1986).

Selected examples of annual average exposure levels estimated for each of these combinations, for each time period, are shown in Tables 2 and 3. Table 2 shows different occupations that are set on a shipping wharf. The occupation of 'fitter' was assessed as having an average exposure level of $0.0531 \mathrm{f} / \mathrm{ml}$ each year between 1943 and 1986, when working on a wharf. The annual average for the periods 1987-2003 and from 2004 onwards was the background exposure level of $0.0001 \mathrm{f} / \mathrm{ml}$. The occupation of 'fitter' exists in many more industries and Table 3 shows the assessments for fitters in the different industries/locations.

The AsbJEM estimates of asbestos exposure levels for each of the industryoccupation combinations, for each time period, can be found in Supplemental Tables S1 and S2. Particularly high annual average asbestos exposure levels for the years before 1987 were estimated for occupations in the asbestos manufacturing industry (up to $12 \mathrm{f} / \mathrm{ml}$ ), as well as among asbestos removalists and insulators (2.44 f/ml). Up until 1986, 46 occupation-industry combinations were estimated to have had exposures exceeding the current Australian exposure standard of $0.1 \mathrm{f} / \mathrm{ml}$. These jobs included artificers, insulators, asbestos removalists, and workers in the manufacturing and transport of asbestos.

Asbestos exposure levels decreased markedly during the period 1987-2003, when higher exposures (i.e. $>0.1 \mathrm{f} / \mathrm{ml}$ as a time-weighted average for an 8-hour working day) were not considered to have occurred any longer. In the latest period (from 2004 onwards) all mode exposure levels were considered to be down to background levels. However, peak exposures still occurred, resulting in slightly increased annual average exposure levels for some occupations such as asbestos removalists and boilermakers/welders.

\section{DISCUSSION}

The AsbJEM was developed based on expert assessments incorporating all available historical exposure data relevant to Australian conditions and provides asbestos 
exposure estimates for all relevant occupations in Australia since 1943. Exposure levels were estimated for 224 occupations in 60 industries. The asbestos manufacturing, shipyard and insulation industries were estimated to have had the highest exposures which declined with time. Over $90 \%$ of exposed occupations included in the AsbJEM were considered to have had exposure to a mixture of asbestos fibres including crocidolite. The AsbJEM can be used to estimate exposureresponse relationships for asbestos-related diseases among Australian workers exposed to asbestos in a range of occupations, industries and time periods.

Occupational exposure assessment studies often make use of experts, such as occupational hygienists, chemists, engineers, and other professionals, to infer exposures from job histories or to estimate exposures based on a review of subjectreported information. Experts are expected to have a better vantage point than subjects themselves: (1) by training, they understand the mechanisms of occupational exposures and know where to find data about them; (2) within the context of a study, they know the types of exposure considered relevant; and (3) based on study data, they have an overview of the range of relevant jobs. Experts are generally considered to provide reliable exposure estimates (Siemiatycki et al. 1997; Teschke et al. 2002).

Quantitative exposure measurements have been described as the best estimates of actual dose (Teschke et al. 2002). However, retrospective exposure data is often incomplete and does not represent all occupations at risk. Although government measurement databases do exist in Australia, they are limited and few have data prior to 1986. Establishment of regular occupational exposure monitoring programs in the Western Australian industry did not commence until after the introduction of legislation in 1984 (DOCEP 1996). Monitoring prior to this date was ad hoc and sitespecific and therefore limited. Furthermore, the majority of data was not collected for research purposes and information on monitoring strategies was often not recorded. Most data were collected for surveillance purposes in industrial settings. Inconsistencies in measurement strategies and sampling techniques complicate distinguishing trends in exposure, which has been reported for other collections of retrospective data on asbestos exposure (Swuste, Dahhan, and Burdorf 2008; Hyland et al. 2010). 
Measurement data, where available, were used in the development of the AsbJEM to assist the expert panel of local industrial hygienists to assign exposure levels. Therefore, the strengths of available monitoring measurements and expert assessments were combined. We used similar methods as have been used for the development of the Finnish JEM (Kauppinen, Toikkanen, and Pukkala 1998). The latter has recently shown to be able to detect the well-known association between asbestos exposure and the risk of mesothelioma (Offermans et al. 2014).

Expert assessments have previously been considered as a "pseudo gold standard" when used in conjunction with measurements of airborne fibre levels (Swuste, Dahhan, and Burdorf 2008). The information from measurement data has enabled the quantification of the categorical exposure levels. However, the experts' opinion was essential to assess data quality and to make the final decision on each cell in the matrix. When assigning exposure estimates for similar occupations for the AsbJEM, the expert panel reviewed the occupations by industry, and then cross-referenced their estimates by job title. This ensured that variation between similar titles would be reflected in the estimates. Due to the absence of adequate exposure measurements for the first time period, estimates were based solely on expert opinion and the literature on consumption and industry practice. From the comments made by the expert panel, it appeared that they were most confident of estimates made for the years between 1967 and 2003.

Asbestos workers, insulators, waterside workers (including shipyard, wharf, navy and marine), carpenters/joiners, boilermakers/welders, power supply and railway workers were estimated to have experienced the highest levels of asbestos exposure. These jobs are consistent with those shown to have a high risk of mesothelioma in Australia (Yeung and Rogers 2001; Leigh and Driscoll 2003).

Overall, estimated annual average exposure levels in AsbJEM may appear relatively low. However, they are similar to full-shift asbestos exposures reported elsewhere. For example, simulation studies on fabricating gaskets yielded average 8-hr TWAs between 0.02 and $0.14 \mathrm{f} / \mathrm{ml}$; exposures between 0.006 and $0.01 \mathrm{f} / \mathrm{ml}$ as $8-\mathrm{hr}$ TWA were reported for electricians; exposures for welders were all below $0.01 \mathrm{f} / \mathrm{ml}$; and concentrations during boiler repair and boiler insulation work ranged from 0.02 to 0.3 
f/ml (Williams, Phelka, and Paustenbach 2007). In AsbJEM, annual average exposure levels for gasket manufacturing were $0.0671 \mathrm{f} / \mathrm{ml}$ prior to 1986 and 0.0025 from 1987 to 2003; electricians were assigned $0.0107 \mathrm{f} / \mathrm{ml}$ and $0.0102 \mathrm{f} / \mathrm{ml}$ in those time periods; and welders and boilermakers were assigned $0.0531 \mathrm{f} / \mathrm{ml}$ prior to 1986 and either 0.0531 or $0.0506 \mathrm{f} / \mathrm{ml}$ from 1987 to 2003 , depending on the industry. Similarities are not unexpected as some of the asbestos exposure levels reported in the international literature helped inform the expert panel during the exposure assessment process, in addition to data available in Australia.

Many asbestos measurements reported in literature result from short-term samples (Williams, Phelka, and Paustenbach 2007). Short-term measurements taken during specific (asbestos exposed) tasks will reveal much higher levels than the actual average exposure of a full work shift over a working year, which was estimated for AsbJEM. Therefore, direct comparison of exposure concentrations from those shortterm measurements with annual average exposure levels is not appropriate. Moreover, when developing a JEM, estimations are aimed to represent the most likely exposure for each cell, here each job-industry-time period combination. A JEM will therefore not capture the whole range of potential exposure levels within each combination, i.e. a JEM does not account for variability between individuals within the same job (Kauppinen, Toikkanen, and Pukkala 1998; Kromhout, Symanski, and Rappaport 1993).

Exposure intensities are likely to fluctuate depending on specific tasks and other workplace circumstances. Therefore two indicators of asbestos exposure intensity (mode and peak), were combined to allow greater specificity between occupational groups. Accounting for different patterns of exposure is considered particularly important where workers with similar job titles may have experienced dissimilar exposures in different industries as a result of their daily tasks. As can be seen in the 'fitter' example in Table 3, the estimated annual average exposure levels (1943-1986) ranged from $0.0002 \mathrm{f} / \mathrm{ml}$ for a fitter in transport to $0.5719 \mathrm{f} / \mathrm{ml}$ for fitters in the asbestos manufacturing. The changes in exposure levels in the next time period (19872003) differed by industry as well. Also the type of asbestos fibre was dependent on the industry: fitters in abattoirs and cold stores were predominantly exposed to amosite and chrysotile, whereas other fitters were exposed to a mixture including 
crocidolite. Fitters in asbestos manufacturing were exposed to a mixture including crocidolite before 1987 and to chrysotile between 1987 and 2003.

The division of the assessments into specific time periods, reflecting changes in asbestos consumption, production and legislation in Australia, allowed for variation in exposure estimates over time. Exposure limits were first recommended in Australia in 1964 at 5 mppcf for all types of asbestos, almost 30 years after exposure controls had been implemented in the US and the UK (Musk et al. 1992). These recommendations were not enforced in Australian legislation until 1978, with the Factories and Shops Act imposing an exposure limit of $2 \mathrm{f} / \mathrm{ml}$ for amosite and chrysotile, and $0.1 \mathrm{f} / \mathrm{ml}$ for crocidolite (Musk et al. 1992). The introduction of exposure limits was accompanied by a marked drop in asbestos consumption after 1980 (Xu et al. 1985), and it is likely that workers' exposures also declined. The further use of all asbestos was prohibited in 2003 (crocidolite in 1986) and the national exposure standard for all asbestos types has been $0.1 \mathrm{f} / \mathrm{ml}$ since (NOHSC 2005). The time-specific estimations in the AsbJEM were similar to those estimated in JEMs from the Netherlands, the US, and Finland (Swuste, Dahhan, and Burdorf 2008; Dement et al. 2008; Kauppinen, Toikkanen, and Pukkala 1998).

Initially, we had identified four time periods of interest based on changes in Australian asbestos consumption and legislation. However, jobs were assigned the same exposure levels by the expert panel in the first two periods (1943-1966 and 1967-1986). Firstly, the expert panel classified occupations on a semi-quantitative scale. A high-exposure job would have been high in both periods. Secondly, asbestos exposure levels generally went up from 1943 onwards because of increased production and availability. Levels started to decrease again in the mid-1960s due to the recognition of health hazards, resulting in improvements in awareness, engineering controls and use of personal protective equipment. As a result, those two periods were considered to have been comparable in terms of exposure overall. Moreover, as indicated above, the experts were less confident about the assignments for the earlier periods, resulting in the same assignments for the first two time periods.

The asbestos type was documented to help identify occupations where exposure was likely to have been to amphiboles (including crocidolite and amosite), which are 
associated with a greater risk for mesothelioma than serpentine (chrysotile) asbestos (Hodgson and Darnton 2000). The potency differences for lung cancer are still disputed. In a recent meta-analysis for lung cancer and asbestos, the slope of the exposure-response relationship was roughly eight times higher for exposure to amphiboles versus chrysotile fibres (Lenters et al. 2011), however the potency of the more typical Australian exposure to mixed fibres, has not been assessed. The vast majority (>90\%) of occupations having exposure to asbestos above background level were assessed as having been exposed to a mixture of amphiboles and serpentine.

The experts assigned a mixture of fibre types, including crocidolite, to a large part of the occupation-industry combinations, because of the widespread use of blue asbestos in Australia. The decision by the expert panel for a fibre type classification other than the mixture including crocidolite was only made for industries that clearly involved other types of asbestos. These industries were abattoirs (amosite), asbestos manufacturing 1987-2003 (chrysotile), coal/diamond mining (chrysotile), cold stores (amosite), gasket manufacturing (chrysotile), insulation factory worker (mixture not including crocidolite), insulation/lagging 1987-2003 (chrysotile) and material handlers 1987-2003 (chrysotile).

AsbJEM can provide a quantified estimate of asbestos exposure for any individual with a history of having worked in Australia, based on knowledge of the person's occupation, the industry or location, year started working and time spent (in months or years) or year finished. Summing the exposure estimates for each year will provide an estimate of the cumulative asbestos exposure that an individual has experienced over his or her working life in this country. This way, the AsbJEM enables characterising the distribution of occupational exposure to asbestos in the Australian population. The AsbJEM will improve the interpretation and prediction of trends in asbestos-related diseases, identification of occupational risks, examination of exposure-response relationships, and estimation of the degree of likelihood that any particular disease was due to a particular episode of past occupational exposure. 


\section{ACKNOWLEDGEMENTS}

The expert panel consisted of Len Gordon, Paul Foley and Neville Blesing, whose input was critical in the development of the AsbJEM. Data and other valuable input were provided by Lindy Nield from the Western Australian Department of Consumer and Employee Protection; Rebecca Hyland from the New South Wales Dust and Diseases Board; Coffey Environments; David Kilpatrick; Michael Kottek; Eva Francis; Timo Kauppinen; Ewan McFarlane; and Philippe Dufresne.

Competing interests: The work presented was supported by the National Centre for Asbestos Related Disease (NCARD) and Svein van Oyen was supported by an Australian Postgraduate Award. Lin Fritschi is supported by a fellowship from the National Health and Medical Research Council. The authors designed and executed the study and have sole responsibility for the writing and content of the manuscript. The study's sponsors did not influence the way the study was structured or carried out, the results or review of the manuscript prior to publication.

\section{REFERENCES}

Australian Mesothelioma Registry 2nd Annual Report. (2012).

Brown SK. (1981) A review of occupational and environmental exposure to asbestos dust. Victoria, Australia: CSIRO: Division of Building Research.

Brown SK. (2000) Asbestos. Chapter 8 in Indoor Air Quality Handbook. Spengler JD et al. (Eds) McGraw-Hill, N.Y.

Cumpston AG. (1978) The Health Hazard at Wittenoom. In: Public Health Department, ed Government of Western Australia.

de Klerk NH, Armstrong BK, Musk AW, Hobbs MS. (1989) Cancer mortality in relation to measures of occupational exposure to crocidolite at Wittenoom Gorge in Western Australia. Br J Ind Med; 46 529-36.

Dement JM, Kuempel ED, Zumwalde RD, Smith RJ, Stayner LT, Loomis D. (2008) Development of a fibre size-specific job-exposure matrix for airborne asbestos fibres. Occup Environ Med; 65 605-12.

Dewes DN. (1986) Controlling asbestos in buildings: an economic investigation. Washington D. C.: Resources for the Future Inc.

DOCEP. (1996) Occupation Health and Safety Regulations. In: Department of Consumer and Employee Protection, ed Western Australian Government, 1996.

Dodic-Fikfak M, Quinn MM, Kriebel D, Wegman D, Eisen E. (2001) Assessment of exposure to chrysotile and amphiboles for a case-control study of the risk of lung cancer among Slovenian asbestos-cement workers. . In: Hagberg M, Knave B, Lillienberg L, Westberg H, eds. X2001 - Exposure Assessment in Epidemiology and Practice. Stockholm, Sweden: National Institute for Working Life; 350-2.

Hodgson JT, Darnton A. (2000) The quantitative risks of mesothelioma and lung cancer in relation to asbestos exposure. Ann Occup Hyg; 44 565-601.

HSE. (1984) Environmental Hygiene: Probable asbestos dust concentrations at construction processes, Guidance Note EH 35. In: Health and Safety Executive, ed. Vol. 35.

Hyland RA, Yates DH, Benke G, Sim M, Johnson AR. (2010) Occupational exposure to asbestos in New South Wales, Australia (1970-1989): development of an asbestos task exposure matrix. Occup Environ Med; 67 201-6. 
Kauppinen T, Toikkanen J, Pukkala E. (1998) From cross-tabulations to multipurpose exposure information systems: a new job-exposure matrix. Am J Ind Med; 33 409-17.

Kromhout H, Symanski E, Rappaport SM. (1993) A comprehensive evaluation of within- and between-worker components of occupational exposure to chemical agents. Ann Occup Hyg; 37 253-70.

Lange JH, Lange PR, Reinhard TK, Thomulka KW. (1996) A study of personal and area airborne asbestos concentrations during asbestos abatement: a statistical evaluation of fibre concentration data. Ann Occup Hyg; 40 449-66.

Lees PSJ. (1989) Air Sampling \& ACMs in Buildings. Symposium on Health Aspects of Exposure to Asbestos in Buildings. Harvard University, Energy \& Environmental Policy Centre: Harvard University.

Leigh J, Driscoll T. (2003) Malignant mesothelioma in Australia, 1945-2002. Int J Occup Environ Health; 9 206-17.

Lenters V, Vermeulen R, Dogger S, Stayner L, Portengen L, Burdorf A, Heederik D. (2011) A meta-analysis of asbestos and lung cancer: is better quality exposure assessment associated with steeper slopes of the exposure-response relationships? Environ Health Perspect; 119 1547-55.

Lin RT, Takahashi K, Karjalainen A, Hoshuyama T, Wilson D, Kameda T, Chan CC, Wen CP, Furuya S, Higashi T, et al. (2007) Ecological association between asbestosrelated diseases and historical asbestos consumption: an international analysis. Lancet; 369 844-9.

Musk AW, de Klerk NH. (2004) Epidemiology of malignant mesothelioma in Australia. Lung Cancer; 45 Suppl 1 S21-3.

Musk AW, de Klerk NH, Eccles JL, Hobbs MS, Armstrong BK, Layman L, McNulty JC. (1992) Wittenoom, Western Australia: a modern industrial disaster. Am J Ind Med; $21735-47$.

NIOSH. (1994) Asbestos and Other Fibres by PCM (Method 7400). In: National Institute of Occupational Safety and Health, ed Government of the United States of America.

NOHSC. (2005) Code of Practice for the Management and Control of Asbestos in Workplaces [NOSHC: 2018 (2005)]. In: National Occupational Health and Safety Commission, ed Australian Government Publishing Services.

Nolan RP, Langer AM. (1989) Fibre type \& Mesothelioma Risk. Symposium on Health Aspects of Exposure to Asbestos in Buildings. Harvard University, Energy \& Environmental Policy Centre: Harvard University. 127-33.

Offermans NS, Vermeulen R, Burdorf A, Goldbohm RA, Kauppinen T, Kromhout H, van den Brandt PA. (2014) Occupational asbestos exposure and risk of pleural mesothelioma, lung cancer, and laryngeal cancer in the prospective Netherlands cohort study. J Occup Environ Med; 56 6-19.

Olsen NJ, Franklin PJ, Reid A, de Klerk NH, Threlfall TJ, Shilkin K, Musk B. (2011) Increasing incidence of malignant mesothelioma after exposure to asbestos during home maintenance and renovation. Med J Aust; 195 271-4.

Price B. (1989) Assessing asbestos exposure potential in buildings. Symposium on Health Aspects of Exposure to Asbestos in Buildings. Harvard University: Energy \& Environmental Policy Centre, Harvard University.

Rushton L, Hutchings SJ, Fortunato L, Young C, Evans GS, Brown T, Bevan R, Slack R, Holmes P, Bagga S, et al. (2012) Occupational cancer burden in Great Britain. Br J Cancer; 107 Suppl 1 S3-7.

Safe Work Australia. (2011) Workplace exposure standards for airborne contaminants.

Siemiatycki J, Fritschi L, Nadon L, Gerin M. (1997) Reliability of an expert rating procedure for retrospective assessment of occupational exposures in community-based casecontrol studies. Am J Ind Med; 31 280-6. 
Swuste P, Dahhan M, Burdorf A. (2008) Linking expert judgement and trends in occupational exposure into a job-exposure matrix for historical exposure to asbestos in the Netherlands. Ann Occup Hyg; 52 397-403.

Teschke K, Olshan AF, Daniels JL, De Roos AJ, Parks CG, Schulz M, Vaughan TL. (2002) Occupational exposure assessment in case-control studies: opportunities for improvement. Occup Environ Med; 59 575-93; discussion 94.

Vermeulen R, Chadeau-Hyam M. (2012) Dynamic aspects of exposure history-do they matter? Epidemiology; 23 900-1.

WA Advisory Committee on Hazardous Substances. (1990) Asbestos Cement Products. Perth, Western Australia: Department of Occupational Health Safety \& Welfare.

Williams PR, Phelka AD, Paustenbach DJ. (2007) A review of historical exposures to asbestos among skilled craftsmen (1940-2006). J Toxicol Environ Health B Crit Rev; 10 319-77.

Woitowitz HJ, Rodelsperger K, Arhelger R, Glesen T. (1983) Asbeststaubbelastung am arbeitsplatz: Messwerte der Internationalen Literatur. Dortmund, Germany: Bundesanstalt für Arbeitsschutz and Unfallforschung.

Xu Z, Armstrong BK, Blundson BJ, Rogers JM, Musk AW, Shilkin KB. (1985) Trends in mortality from malignant mesothelioma of the pleura, and production and use of asbestos in Australia. Med J Aust; 143 185-7.

Yeung P, Rogers A. (2001) An occupation-industry matrix analysis of mesothelioma cases in Australia 1980-1985. Appl Occup Environ Hyg; 16 40-4. 